\title{
OS EDITORIAIS DA REVISTA EDUCAÇÃO E FILOSOFIA DA UNIVERSIDADE FEDERAL DE UBERLÂNDIA: UMA PRIMEIRA ANÁLISE
}

Maria Dulcinea da Silva Loureiro* André Marcio Picanço Favacho*

\section{RESUMO}

O presente artigo propõe-se a fazer uma reflexão sobre a Revista Educação e Filosofia da Universidade Federal de Uberlândia, tendo como objeto de análise os seus editoriais. Inicialmente, descreveremos a trajetória da Revista em seus 17 anos de existência e, para isso, faremos uma rápida incursão no seu ciclo de vida, com o intuito de acompanhar as mudanças ocorridas, tanto no seu aspecto técnico - referente à organização, publicação e editoração da revista - quanto no conteúdo dos seus editoriais. Em seguida, deter-nos-emos na análise dos editoriais, pois compreendemos que os mesmos assumiram, durante muito tempo, o papel de porta vozes dos inconformismos com a política social, educacional, e com os encaminhamentos econômicos que estavam sendo postos em prática com a política neoliberal.

PALAVRAS-CHAVE: Revista Educação e Filosofia. Editorial. Educação Superior.

\section{ABSTRACT}

This article aims at discussing the Educação e Filosofia published by the Federal University of Uberlandia in the state of Minas Gerais,

* Professora da Universidade Regional do Cariri - URCA.

** Professor da Universidade do Estado de Minas Gerais - UEMG. 
Brazil, specifically analyzing its editorials. As a start, the magazine's seventeen year history will be described through incursions into its cycle of life, with the objective of accompanying changes which have occurred both in its technical aspects such as organization, publication and editing and in the content of its editorials. Secondly its editorials will be the main focus of the analysis, with the hypothesis that they assumed for a long time the voices of those who refused to accept the status quo of social and educational policies as well as the direction of economic policy being taken by the neo-liberals.

KEYWORDS: Magazine Educação e Filosofia. Editorials. Superior Education.

\section{Considerações iniciais}

O presente artigo propõe-se a fazer uma reflexão sobre a Revista Educação e Filosofia da Universidade Federal de Uberlândia, tomando por objeto de análise os seus editoriais. Em geral, o trabalho de análise de editoriais justifica-se pela relevância que os mesmos assumem no interior dos periódicos, dando a devida visibilidade a outros elementos do cotidiano das revistas que, por assim dizer, foram eliminados pelos processos técnicos de sua elaboração. Além disso, os editoriais das revistas acadêmicas trazem à tona, ou deveriam trazer, as contestações e insatisfações sobre a conjuntura social, política e educacional do país, e são, nesse sentido, uma espécie de crônica do panorama contemporâneo.

Em se tratando de uma revista que une dois importantes campos do conhecimento (educação e filosofia), pode-se dizer que os seus editoriais representam um valioso instrumento de compreensão da realidade acadêmica. Quer por omissão ou por demonstração das polêmicas, os editoriais ainda assim são excelentes filmes sobre o real das produções universitárias.

Pensar a educação a partir da análise das revistas e periódicos é consentir, sobretudo, que estes materiais/documentos nos dão 
acesso aos testemunhos capilares que se manifestaram nos cotidianos dos colaboradores das revistas, pois são nesses periódicos que os estudiosos e pesquisadores ensaiam pensamentos e juízos acerca dos acontecimentos, o que, indubitavelmente, os documentos oficiais, como leis e decretos, e até mesmo livros, não nos permitem alcançar. Por conseguinte, esse consentimento constitui-se em um pressuposto para a análise de editoriais. Ou seja, acredita-se que os editoriais podem nos fornecer de forma mais livre e independente - até mais que os próprios artigos que compõem a revista - uma razoável crítica da própria produção e divulgação do conhecimento e das políticas envolvidas nessa produção. Nóvoa (1997) garante que

[...] a análise da imprensa permite apreender discursos que articulam práticas e teorias, que se situam no nível macro do sistema mas também no plano micro da experiência concreta, que exprimem desejos de futuro ao mesmo tempo que denunciam situações do presente (1997, p. 11).

Assim, por meio da análise do referido periódico e dos discursos proferidos nos seus editoriais, pudemos entrever a teia de relações que perpassam, neste caso específico, o campo educacional e científico nas suas múltiplas relações com os espaços sociais e políticos. Bastos faz-nos lembrar que

O estudo do lugar da imprensa pedagógica no discurso social, as estratégias editoriais face aos fenômenos educacionais e sociais, revela-se rico de observações ao pesquisador, para o resgate do discurso pedagógico, das práticas educacionais, do cotidiano escolar, do grau de submissão dos professores aos programas e instruções oficiais, da ideologia oficial e do corpo docente, a força de inovação e continuidade que representa, as contradições do discurso (1997, p. 48).

Dessa forma, tentaremos descrever a trajetória da referida Revista em seus 17 anos de existência e, para isso, faremos uma rápida incursão no seu ciclo de vida, com o intuito de acompanhar 
as mudanças ocorridas, tanto no seu aspecto técnico - referente à organização, publicação e editoração da revista - quanto no conteúdo dos seus editoriais. Alguns questionamentos nos orientam: por que publicar uma Revista abrangendo duas áreas do conhecimento, educação e filosofia? Quais as problemáticas educacionais e filosóficas que receberam maior ênfase? Quem escreve na Revista? Em seguida, deter-nos-emos na análise dos editoriais, propriamente ditos, pois compreendemos que os mesmos assumiram, durante muito tempo, o papel de porta vozes dos inconformismos com a política social, educacional, e com os encaminhamentos econômicos que estavam sendo postos em prática com a política neoliberal. Este caráter de contestação já se encontra no editorial número 1 da Revista ao enfatizar que "dentro do princípio de que o caráter objetivo e preciso do conhecimento científico não é compatível com os inconformismos diante das injustiças de toda ordem, pretendemos, ainda, ser um estímulo aos balanços críticos" (1986).

\section{A Revista Educação e Filosofia: breve trajetória}

Em julho de 1986 foi publicada a Revista Educação e Filosofia do Departamento de Pedagogia ${ }^{1}$ da Universidade Federal de Uberlândia, fruto de um "sonho antigo e de um inconformismo com a falta de um veículo como este, entre nós" (ed. n. 1). Segundo o Estatuto ${ }^{2}$ da Revista, ela

Art. $1^{\circ}[\ldots]$ foi criada pelo Conselho do Departamento de Pedagogia da Universidade Federal de Uberlândia (UFU) em reunião de 18 de dezembro de 1985. A partir da cisão desse Departamento, ocorrida em 29 de maio de 1987, a responsabilidade pela Revista transferiu-se aos departamentos resultantes: Departamento de Fundamentos da Educação, Departamento de Filosofia e Departamento de Princípios e

1 Na data de criação da revista ainda não existia o curso de Filosofia, que será criado em 1991.

2 Esta é a última versão do Estatuto, aprovada em 23 de maio de 2003.

Educ. e Filos., Uberlândia, v. 20, n. 40, p. 111-136, jul./dez. 2006. 
Organização da Prática Pedagógica. Finalmente, desde $1^{\circ}$ de janeiro de 2000, a Revista está vinculada à Faculdade de Educação e ao Departamento de Filosofia da FAFCS.

Em 1997, o Programa de Mestrado em Educação passou a ter representantes no conselho editorial da Revista.

A Revista já completou 17 anos, com $33^{3}$ números publicados e procurou contribuir para a reflexão da educação e da filosofia, não só do Triângulo Mineiro, mas de todo o território nacional. A Revista, que faz permuta ${ }^{4}$ com outras revistas nacionais e estrangeiras, tem procurado atingir o objetivo a que se propôs, ou seja, o de ser um "fórum permanente de debates a todo educador, a todo pensador e, sobretudo, a todo pensador-educador", conforme o editorial do primeiro número da Revista, ratificado no número 20, quando ela completara 10 anos de existência.

É notório que a Revista já nasceu sob a égide de uma publicação interdisciplinar, posto que contempla duas áreas do conhecimento, a educação e a filosofia, procurando ainda realizar incursões em outros campos do saber. Disso resultam, no decorrer da sua trajetória, artigos das mais diferentes áreas afins como Sociologia, Psicologia, Geografia, entre outras. Esse caráter interdisciplinar, próprio da constituição da Revista, encontra-se enfatizado em vários editoriais, nos quais se procurou demonstrar que esse objetivo é alcançado no conjunto dos trabalhos veiculados nas publicações.

A administração da Revista é feita conjuntamente pela diretoria e pelo conselho editorial. A primeira tem função executiva e o segundo função deliberativa. Ela é definida num processo de eleição, em que podem concorrer todos os professores lotados na Unidade Acadêmica e nos Departamentos responsáveis pela Revista, para um mandato de dois anos.

3 Segundo informação do prof. Décio Gatti, o número 34, referente a julho/ dezembro de 2003, já se encontra no prelo.

4 Segundo os dados da lista de periódicos que fazem permuta com a revista, encontramos 192 permutas nacionais e 211 internacionais da Revista Educação e Filosofia, v. 14, n. 32, jan./jun. 2003. 
No entanto, algumas mudanças ocorreram na constituição da diretoria da revista. Por exemplo, de 1986-1993 ela é composta pelo Diretor-Geral, o Secretário e o Tesoureiro; em 1994-1999 passa a ter mais dois cargos: um Diretor de Divulgação e um Diretor de Editoração. Essa mudança se deu, provavelmente, com o objetivo de não sobrecarregar a Direção da Revista. Em 2000, com a aprovação do novo estatuto, no artigo $45^{\circ}$, são estabelecidas as seguintes diretrizes:

A Diretoria se comporá dos seguintes cargos a serem exercidos por professores da respectiva Unidade Acadêmica e Departamento: Diretor Geral, Secretário, Diretor de Editoração na área de Filosofia, Diretor de Editoração na área de Educação, Diretor de Divulgação da área de Filosofia, Diretor de Divulgação da área de Educação.

O editorial de n. 14 (1993) testemunha o favorecimento obtido pela nova composição da diretoria, pois certifica que a divisão do trabalho para a elaboração da Revista superou muitas dificuldades. Garante que foi o primeiro a "beneficiar-se da divisão do trabalho de editoração de um especialista do campo da educação e outro da filosofia, objetivando maior agilidade e rigor na análise dos textos originais recebidos e na publicação do periódico" (1993). Estas mudanças serão acompanhadas de reformas na apresentação visual, diagramação e fonte, com o objetivo de facilitar o processo de leitura. ${ }^{5}$

A revista começa com uma tiragem de 1000 exemplares. Pouco tempo depois, passa para 1500, até o volume 7, n. 14 (1993). Contudo, o n. 15 (1994) da Revista volta a ter uma tiragem de 1000 exemplares. Do n. 16 (1994) até o n. 18 (1995) a Revista volta a produzir 1500 exemplares. Observa-se esta oscilação em toda a trajetória da Revista, de modo que do n. 19 (1996) até o 28 (2000), a tiragem ficará entre 1000 e 1500 exemplares. No entanto, no n.

5 Estas informações estão contidas no editorial do v. 14, n. 27/28, 2000.

Educ. e Filos., Uberlândia, v. 20, n. 40, p. 111-136, jul./dez. 2006. 
29 (2001) da Revista ocorrerá uma redução significativa da tiragem, que passará a ser de 800 exemplares. Esta redução se constituirá numa nova oscilação, desta vez, entre 800 e 1000 exemplares.

O estatuto da Revista, ${ }^{6}$ na Seção I, Art. $6^{\circ}$, Inciso III, atribui como competência da Diretoria a definição tanto do número de páginas de cada seção como também a tiragem da Revista. Parece paradoxal já que, à medida que a Revista se consolida, tanto no rigor da sua produção - considerada pela ANPED de 1997 entre os 20 melhores periódicos brasileiros na área de Educação e Filosofia $^{7}$-, quanto nas permutas que realiza, com periódicos nacionais e internacionais, haja uma redução na sua tiragem. Não há na Revista nenhuma explicação mais direta para a redução da tiragem, a não ser as constantes denúncias das dificuldades financeiras pelas quais a Universidade passa e, secundariamente, o atraso tecnológico da gráfica. ${ }^{8}$

A revista não apresenta nenhuma informação sobre o número de assinantes. No editorial de n. 20 (1996) relata-se apenas que os "membros das primeiras diretorias levavam os números da Revista a Congressos e aos cursos de pós-Graduação para proceder à necessária divulgação".

Em relação às seções que compõem a Revista (anexo A), pudemos verificar, pela sua obviedade, que a seção de artigos e de resenhas encontra-se em todos os números publicados, com exceção do número 17 em que não aparece a seção de resenhas. Contudo, a seção de debates está presente em apenas 12 números da Revista (anexo D), e tem como predominância os trabalhos publicados na área da educação. A seção de notícias aparece nos três primeiros números e depois no n. 26 (1999). A seção de comunicações, que tem por objetivo dar visibilidade aos trabalhos apresentados pelos professores em eventos científicos na forma de comunicação, ${ }^{9}$ aparece em dez números (anexo 01). No n. 27/28 (2000) aparece

\footnotetext{
6 Vale lembrar que estamos trabalhando com a última versão do estatuto.

7 Conforme o editorial do n. 21/22, 1997.

8 Essa reflexão aparece no editorial no n. 24, 1998.

9 Conferir editorial n. 03, 1987.
} 
uma seção com o nome "tradução". A seção de Resumos de Teses e Dissertações passa a fazer parte da Revista a partir do n. 14 (1993).

A quantidade de artigos em cada Revista gira em torno de sete a vinte. Imagina-se que esta variação esteja relacionada com o número de páginas de cada periódico e com a quantidade de artigos encaminhados e aprovados pelo conselho editorial da revista. $\mathrm{O}$ levantamento feito mostra que 10 números da revista têm entre 100 a 200 páginas, e os 19 números restantes têm de 250 a 300 páginas.

As temáticas contempladas na revista, tanto de educação quanto de filosofia, são as mais variadas possíveis, caracterizandose pela dispersão de temas. Os artigos sobre educação tratam de temáticas que passam pela metodologia de ensino (Geografia, Ciências, Matemática), formação de professor, currículo, avaliação, educação e movimentos sociais, alfabetização, política educacional, história da educação, fundamentos da educação, educação de jovens e adultos, pesquisa em educação, interdisciplinaridade, dentre outras. Observa-se, no entanto, um número acentuado de artigos que abordam a história da educação.

Os artigos de Filosofia tratam de temáticas como: mito, o conceito de tempo, democracia, cidadania etc. Sobre as correntes filosóficas atestam: estruturalismo, positivismo, materialismo histórico-dialético, Filosofia humanista e moderna, que são discutidas à luz da filosofia política, ética, lógica, estética e antropologia.

Em um levantamento feito a partir dos títulos dos artigos publicados encontramos os seguintes filósofos mais contemplados: Kant, Hegel, Marx, Merleau-Ponty e Heidegger Aristóteles, Adorno, Descartes, Kierkegaard, Hannah Arendt e Sartre, Frege, Kuhn, Horkheimer, Habermas, Hobbes, Rousseau, Hume, Wittgenstein, Platão, Sócrates, Walter Benjamin, Marcuse, Montaigne, Engels, Gramsci, Nietzsche, Vico, Proudhon, Foucault, Abelardo, Husserl, Jean Ladriére, Deleuze, P. Ricouer.

É importante ressaltar que uma análise prévia dos artigos ${ }^{10}$

${ }^{10}$ Essa análise serviu de base para a categorização dos textos em filosofia, educação, filosofia da educação e outros.

Educ. e Filos., Uberlândia, v. 20, n. 40, p. 111-136, jul./dez. 2006. 
publicados revela um equilíbrio (ver o anexo C) nas áreas da filosofia e da educação, o que é constantemente enfatizado em alguns editoriais. Tal equilíbrio traz à tona a preocupação da Diretoria e do Conselho Editorial em contemplar a problemática da educação, da filosofia e da filosofia da educação, a fim de cumprir com os objetivos a que se propõe a publicação. Essa perspectiva interdisciplinar revela-se não só na interface entre educação e filosofia, mas se amplia nos artigos que abordam as problemáticas da sociologia, psicanálise, pesquisa, história, entre outras.

Quanto à destinação da revista, há um paradoxo, a saber: que a revista não terá uma pretensão de se fixar no público acadêmico. No entanto, a natureza dos artigos direciona-se, essencialmente, a um público acadêmico, o que é reforçado pela opção de uma revista editada para especialistas, ${ }^{11}$ e não para um público mais amplo. Numa rápida incursão aos autores dos artigos, notamos, de um lado, a presença de acadêmicos da UFU e, de outro, uma pulverização de acadêmicos das mais diferentes Universidades do país e do exterior, o que prova o caráter não endógeno do periódico.

\section{Análise dos Editoriais}

Durante a leitura dos editoriais para a realização deste texto muitas questões foram surgindo, que não poderiam ser exploradas num trabalho como este. Seria preciso mais tempo e material de pesquisa para compreendê-las. Do conjunto dessas questões, destacamos o caráter de contestação dos editoriais, sobretudo até o número 25 da Revista.Verificamos que essa era uma marca relevante para a Revista em questão e que, portanto, deveria ser um ponto a ser explorado por nós.

Assim, a análise dos editoriais se norteará por duas questões imbricadas. A primeira se refere aos objetivos que são apresentados no primeiro editorial, visando perseguir a forma pela qual os

${ }^{11}$ Conforme reflexão realizada pelo Prof. Bento Itamar Borges, no Edital n. 26 de 1999. 
editoriais o cumprem. A segunda é perceber o caráter que esses editoriais assumem no desdobramento desses objetivos.

Daremos atenção especial ao primeiro editorial, pelo fato de o mesmo possuir um caráter inaugural, que traduz os debates anteriores à construção da Revista, que correspondem, por exemplo, à necessidade da sua criação, dos estatutos, dos embates internos com seus pares na constituição de um espaço de veiculação da produção acadêmica local. É importante salientar que os primeiros editoriais estão marcados por esse traço de sedimentação da proposta da Revista.

Quanto aos desdobramentos, enfatizaremos os conteúdos referentes às concepções de sociedade, de Universidade e de editorial, subjacentes aos textos escritos nesse espaço da Revista.

Buscamos assim, nas opiniões dos editores, as marcas que anunciavam o cumprimento dos objetivos fundantes da Revista. Contudo, essas marcas não se referem apenas ao cumprimento ou não dos objetivos dos editorais mas, sobretudo, a um conjunto de idéias, concepções e valores que dão visibilidade às concepções que norteiam as representações daqueles que produzem a Revista.

No entanto, essa visibilidade mencionada acima não encerrava uma visão unilateral de representações sociais. Os editoriais, apesar de traduzirem uma intencionalidade coletiva, também se revelam pelas singularidades daqueles que os escrevem. Singularidades que se destacam pelas relações de força que seus atores vivenciam no espaço de produção acadêmica, política e filosófica. De modo que, os editoriais expressam materialmente as mudanças sociais, e não simplesmente o pensamento de seus editores, mas, sobretudo, as mudanças das interpretações de mundo que se configuram numa crítica social e política acadêmica.

É importante deixar claro que os editoriais são assinados pelos seguintes professores: prof. Geraldo Inácio Filho, que fará parte da diretoria da Revista por quase dez anos, ${ }^{12}$ e assinará o editorial

${ }^{12}$ Mesmo quando o prof. não está na direção ele se faz presente, ou no conselho editorial ou como consultor da Revista. 
em 12 números da Revista; o prof. Bento e a profa . Marilza assinam, respectivamente, três editoriais cada; a prof. Regina Célia assina dois editoriais; os profs. Décio Gatti e Humberto assinam o editorial do número 27/28; e o prof. Wagner também é responsável por um editorial. Alguns editoriais são assinados pela diretoria e o primeiro não tem assinatura (conferir o anexo E).

O Editorial ${ }^{13}$ da Revista passou por mudanças no decorrer da sua trajetória que expressam as diferentes interpretações e opiniões de seus editores e do próprio corpo editorial. Tais mudanças nos obrigaram a buscar mecanismos de análises para os mesmos. Resolvemos classificá-los em três categorias que revelavam os aspectos de sua natureza. Assim, os categorizamos em: (1) editoriais de análise de conjuntura; (2) editoriais de informações sobre a própria Revista; e (3) editorais de apresentação dos textos publicados. Quanto aos primeiros editoriais, percebemos que dão ênfase a duas subdivisões: a primeira trata-se da conjuntura social e política, e a segunda da conjuntura acadêmica, nos quais são encontrados os editoriais de reflexão sobre a educação e a universidade. Quanto aos segundos e terceiros editoriais são, por assim dizer, editoriais mais simples e menos propositivos.

Em razão do objetivo desse texto, iremos discutir apenas a primeira das categorias dos editoriais (os editoriais de análise de conjuntura), encontrados na Revista Educação e Filosofia. Quanto às duas outras categorias de editoriais, infelizmente deixaremos para outra oportunidade, uma vez que elas são, de alguma forma, resultados da análise que se segue.

\section{Editoriais de análise de conjuntura}

Os sociólogos costumam dizer que uma boa análise de conjuntura requer jamais confundir um acontecimento com um fato. Mas essa distinção nem sempre é muito simples de ser realizada. Mesmo para os filósofos esta é uma questão delicada.

${ }^{13}$ Conferir anexo F. 
No kantismo, por exemplo, "um fato é tudo que é objeto de experimentação, isto é, que se pode manifestar no tempo e no espaço através da intuição sensível e segundo as leis do entendimento". Um outro exemplo da dificuldade em se separar acontecimento de fato está em Wittgenstein, para quem "o mundo é a totalidade dos fatos, não das coisas" (JAPIASSU, 1996, p. 100).

Para grande parte dos sociólogos, um acontecimento é fruto de uma série de articulações entre o indivíduo e a sociedade, entre os indivíduos e a política, entre as relações do poder político e o comportamento social. Enfim, são sempre ocorrências que afetam em larga escala as pessoas, enquanto os fatos são relações isoladas quase sempre fragmentadas. Por exemplo, o nascimento do filho de um operário não cria o mesmo impacto do nascimento do filho do Rei, ou a traição cometida a um simples homem de uma comunidade qualquer não é igual à traição de Judas.

Contudo, esses dois últimos registros sobre a diferença entre acontecimento e fato nos indicam que, talvez, os sociólogos tenham reduzido o fato à coisa. A diferença entre o fato e o acontecimento, nesse sentido, restringe-se a uma amplitude do acontecido, o que definitivamente não coincide com a perspectiva filosófica. No entanto, a demarcação da diferença entre fato e acontecimento, tão requisitada pelos sociólogos, possui seu valor, pois o pensamento social já tem para si que um fato quase sempre se limita às grandes datas históricas de determinados episódios (científicos), mas que na verdade não representa, de forma alguma, os acontecimentos de uma outra história (fatos sensíveis) que se situa no subsolo desses fatos, paralisada por um discurso competente.

Tomar os acontecimentos sociais não apenas como um fato isolado, significa não tê-los como

[...] uma decisão, um tratado, um reino, ou uma batalha, mas uma relação de forças que se inverte, um poder confiscado, um vocabulário retomado e voltado contra seus utilizadores, uma dominação que se enfraquece, se distende, se envenena e uma outra que faz sua entrada, mascarada (FOUCAULT, 1979, p. 28). 
O duplo nó existente na noção de acontecimento em Foucault, releva-nos o dinamismo que as práticas sociais representam. Em outras palavras, o acontecimento, nesse sentido, não respeita nenhuma linearidade. Assim, não cabe nem a relação do longínquo ou a do próximo, nem é puro episódio isolado, nem tampouco a amplificação do acontecido; não é passado, mas talvez seja uma multidão de "erros", em que todos nós nos sujeitamos e nos libertamos das práticas de dominação.

Boa parte dos editoriais analisados por nós parece se situar nessa direção. São em sua grande maioria "análises de conjunturas", seja da realidade social e política, seja da educação, da filosofia ou da universidade. Tais editoriais denunciam o sistema econômico, ao mesmo tempo em que o reconhecem em nossas práticas educativas. Em geral, esses editoriais mostram a estreita ligação que há entre as práticas dos educadores no interior da faculdade e o universo político, econômico e filosófico da sociedade atual. Quase sempre as análises concluem que as práticas dos educadores endossam, de certa forma, determinadas políticas vindas do sistema contra a categoria docente e contra os próprios alunos. Esses editoriais destacam três bons exemplos que demonstram a relação entre prática educativa e sistema econômico. O primeiro exemplo é a clássica reivindicação feita por professores e alunos a favor da prática em detrimento da teoria (conferir editoriais de n. 2, 1987 e n. 16, 1994). Essa reivindicação, se não for problematizada, acaba por contribuir para o sucateamento da educação superior, pois o Estado exige do educador competência teórica, mas não oferece as condições objetivas para isso. Assim fica claro que o Estado transformou o educador num prático, ou seja, num mero subordinado às metodologias e às técnicas.

Um outro exemplo se dá quando os educadores se dizem progressistas ${ }^{14}$ e reprovam seus alunos sob o argumento do baixo nível de intelectualidade dos mesmos, ou seja, essa postura

${ }^{14}$ Essa discussão está presente em vários editoriais, mais especificamente nos das Revistas n. 13 (1993), 14 (1993), 16 (1994). 
aproxima-se da política de avaliação da universidade pública que também qualifica ou desqualifica o professor pela sua produtividade (artigos, livros, teses); e, um último exemplo, é o professor que vê a impossibilidade da iniciação científica na graduação em razão do baixo nível teórico dos alunos, enquanto a política pública pensa o mesmo dele (e dos próprios alunos). Assim, o professor e o Estado promovem cada vez mais a elitização do ensino superior, ou seja, impedem a formação de outros intelectuais para esta sociedade.

O duplo nó dos acontecimentos, evidenciados nesses exemplos retirados dos editoriais, parece funcionar da seguinte maneira, a saber: o professor que combate a política desqualificadora do Estado contra a Universidade é o mesmo que desqualifica os alunos. $\mathrm{Ou}$, parece-nos que contra a Universidade estão o Estado, o professor e, por vezes, os próprios alunos. Ou ainda, ninguém está contra ninguém, mas todos estão contra a produção da crítica.

É obvio que esses editoriais não prezam por um imobilismo ou relativismo da situação política da sociedade, pelo contrário, são ferozes na forma de inferir a realidade. Não são pessimistas, mas são profundamente provocativos, pois instauram um mal-estar bem indesejável para alguns - alunos, professores ou próprias políticas de Estado. No entanto, o tipo de editorial que faz essa análise de conjuntura ${ }^{15}$ parece estar com dias contados ou senão já vencidos, pois é notório o seu enfraquecimento e, porque não dizer, o seu desaparecimento nos últimos volumes publicados pela Revista analisada.

O enfraquecimento ou envenenamento, como nos diria Foucault, é, a nosso ver, a outra dominação que se mascara e se instala no

\footnotetext{
${ }^{15}$ No editorial de n. 25 (1999) encontramos a seguinte afirmação: “Enquanto esta seção existir - e trata-se na verdade, de um gênero da literatura acadêmica já extinto em alguns periódicos -, os editores a aproveitarão para fazer rápidas análises de conjuntura nacional e, em particular, da política acadêmica". Paradoxalmente, é a partir deste número da revista que os editoriais assumirão a função de apenas trazer informações sobre a revista e de fazer a apresentação dos textos publicados no periódico.
} 
atual momento histórico. Não como simples dominações da ordem direta, isto é, vindas apenas de cima para baixo, mas como complexos desdobramentos dos acontecimentos que, como acabamos de demonstrar, são, por assim dizer, acontecimentos que se formam, via discurso, nas micro-relações entre os sujeitos.

Embora os editoriais de análise de conjuntura tenham criado esse tipo duplo de combate (ao Estado e às próprias práticas educativas), eles não se filiaram, aparentemente, a nenhuma tendência filosófica explícita. Isso aponta para uma fidelidade aos objetivos da Revista que é "dinamizar os debates das questões relacionadas com os temas Educação e Filosofia". Tentam, dessa forma, sustentar um outro objetivo, talvez mais direto, que é o compromisso da Revista em ser um "ESPAÇO ABERTO À DISCUSSÃO QUE TEM POR OBJETIVO A CONSTRUÇÃO CONSCIENTE DESTE PAÍS" (destaques do autor). Tanto a "construção consciente" como a "dinamização dos debates" entre ambas faculdades são, a nosso ver, perspectivas que se concretizam pela via editorial. Entretanto, estes editoriais ${ }^{16}$ partem do pressuposto de que

[...] seria ingênuo imaginar que o sistema científico se organiza e se desenvolve de forma autônoma. O ideal da auto-organização da ciência confronta-se cotidianamente com as injunções da política científica governamental, sob pena de inviabilizar-se em função do alto custo de sua realização (TRINDADE, 1999, p. 19).

A crítica que os editoriais fazem à elitização das universidades, à falta de autonomia e ao modelo neoliberal desmascara a concepção de Universidade que o Estado brasileiro defende, ao transformar o direito à educação em serviço. Ou, como bem sintetizou Marilena Chaú, ao dizer que o modelo neoliberal

${ }^{16}$ Mais especificamente os editoriais de n. 13 (1993), "Ciências humanas e educação"; n. 14 (1993), "Iniciação científica na graduação"; n. 16 (1994), “Teoria e prática na formação docente", e de n. 23 (1998), "Contradições: iluminismo X populismo". 
[...] percebe a universidade como prestadora de serviços, confere um sentido bastante determinado à idéia de autonomia universitária, e introduz o vocabulário neoliberal para pensar o trabalho universitário, como transparece no uso de expressões como "qualidade universitária", "avaliação universitária" e "flexibilização da universidade" (1999, p. 214).

Tal crítica trás à tona algumas questões: qual a função da Universidade? O que significa uma educação de qualidade? Qualidade para quem?

A Universidade moderna que nasceu sob a égide do pensamento Iluminista, do desenvolvimento das ciências e da Revolução Francesa, se vê às voltas com um novo panorama, como este destacado por Trindade:

Se o debate universitário posterior à rebelião estudantil de maio de 68 trouxe à discussão o conflito entre a idéia de universidade "liberal" versus universidade "funcional", neste final de século um dos desafios centrais da universidade latino-americana é como estabelecer o equilíbrio entre qualidade, pertinência e eqüidade, numa instituição que deve formar para o desconhecido (TRINDADE, 1999, p. 10).

Trindade expõe o não-horizonte da universidade, a formação para o nada, para o desconhecido, para o inesperado e, por conseguinte, demonstra sua mediocridade, sua fraqueza e redenção aos parâmetros mercadológicos em que ela está submetida.

Ristoff (1999) afirma algo parecido ao dizer que a educação superior e, em especial, a brasileira, enfrenta três grandes crises: a financeira, a do elitismo e a de modelo. Segundo Ristoff, a crise financeira é um "matador silencioso", porque vai minando por baixo e "expressa bem o processo de deteriorização gradual, e por isso é menos impactante e perceptível, do próprio ambiente educacional" (p. 203). A crise do elitismo "é uma crise quantitativa com enorme impacto qualitativo sobre a vida futura da sociedade brasileira" (p. 205). No Brasil apenas $10 \%$ da população na faixa 
etária apropriada tem acesso à educação superior, o que nos torna um país altamente elitista (RISTOFF, p. 206). A "crise de modelo" é resultante do lugar que se ocupa a função da educação superior. Afirma ainda que "é importante lembrar que estamos falando de "educação superior" e não em universidade.

Hoje, queiramos ou não, temos de reconhecer que a educação superior é uma atividade de múltiplas funções (RISTOFF, p. 206). Além disso, instala-se um sistema hierárquico em que as atividades de ensino, pesquisa e extensão não são mais indissociáveis. Essas orientações, segundo Ristoff, não surgem por acaso:

Elas expressam a percepção de três grandes necessidades importantes e legítimas que precisam ser consideradas: a) a necessidade de garantir o avanço autônomo e desatrelado do conhecimento; b) as necessidades do Estado, em geral ditadas pelos projetos de desenvolvimento de governos e pela demanda de mão-de-obra altamente qualificada; c) as necessidades do indivíduo, ditadas pelo seu desejo e pelo seu direito de investir em si próprio (1999, p. 207).

A crise de modelo é também denominada por Cunha (1999) como uma crise de identidade. "Essa crise de identidade resulta do fato de que a instituição não se reconhece e nem é reconhecida mais tão facilmente como no passado" (CUNHA, p. 133). Tal crise passa pela extinção do regime das cátedras, organização dos departamentos, da organização da pós-Graduação e junta-se à crise financeira, reforçando o elitismo.

Assim como Trindade, Ristoff, Chauí, Cunha, entre outros, os editoriais da Revista Educação e Filosofia mostram a concepção de universidade que foi gerida pelo modelo neoliberal de educação, e como essa concepção refletia-se na prática dos docentes. É notório, portanto, que a questão subjacente aos editoriais era, sem dúvida, o lugar que a educação superior e a universidade brasileira deveriam ocupar frente à sua ruína.

Ressaltamos, contudo, que nem todos os editoriais de análise de conjuntura são iguais. Curiosamente, um único editor é quem 
melhor conseguia levar a cabo esta análise de conjuntura, a qual considerava o duplo nó dos acontecimentos entre Estado, Universidade e práticas docentes. Claro que estamos aqui considerando que os sujeitos são diferentes, e que os motivos e estilos de escrita são resultados de experiências construídas ao longo da trajetória de cada um. Mas, se tomarmos a experiência como "a correlação, numa cultura, entre campos de saber, tipos de normatividade e formas de subjetividade" (FOUCAULT, 1985, p. 10), teremos que inferir uma resposta a esse acontecimento, ou seja: que uma determinada relação de força tem sido exercitada pelos próprios editores da Revista ao se prestarem a editoriais tão simples que pouco expressam o intenso mal-estar dos problemas políticos, filosóficos e educacionais.

De qualquer forma, o nosso juízo sobre essa questão não deve ser levado ao "pé da letra", até porque nem todos os editoriais simples são descompromissados com o mal-estar vivido pela atual sociedade. Alguns editores estão apenas cansados de dizer sempre as mesmas coisas, ou, de tão aborrecidos com as condições objetivas de manutenção da Revista, preferem dizer pouco para não complicarem ainda mais as coisas, é o caso, por exemplo, das publicações de volume duplo, causadas pelos atrasos financeiros para manutenção da Revista.

Obviamente, a nossa análise não traz nenhum ponto final quanto a estes editoriais, considerados por nós como simples. Existem muitos outros fatores a serem observados, como por exemplo: quem lê o editorial de uma Revista? Em qual época as pessoas liam freqüentemente os editoriais? Por que pararam de ler? Quem escrevia esses editoriais? Por que uma determinada Revista nasce? Qual é a pontuação que o $\mathrm{CNPq}$ e o $\mathrm{MEC}^{17}$ destinam para quem escreve um editorial?

Passaremos agora aos editoriais de análise de conjuntura que não realizam o duplo nó dos acontecimentos e nem fizeram uma análise de forma simples.Trata-se de editoriais que excluíram as

${ }^{17}$ Ver editorial n. 24, (1998). 
práticas educativas dos professores e centram esforços nas denúncias do sucateamento da Universidade. Na medida em que esses editoriais assim procederam, eles, infelizmente, abandonaram a relação política-sociedade-educação e filosofia.

De certa maneira, esses editoriais quebraram um pouco o objetivo de se dinamizar os debates entre educação e filosofia. Esses editoriais preferiram as práticas de denúncia, muito mais próximas das que fazem os sindicatos. Grosso modo, são panfletários e se prendem numa única temática. A temática mais recorrente é a denúncia do processo de mundialização capitalista. Tais editoriais não são ruins ou bons, eles são denunciadores da grande catástrofe capitalista que estamos vivendo na era da globalização.

Ora, na verdade todos os editoriais de análise de conjuntura têm obrigação de considerar a questão da mundialização e da globalização capitalista, o problema é que esses editoriais privilegiaram a relação capitalismo e universidade, esquecendose, portanto, da relação educação e filosofia, ou, pelo menos, não a mencionaram com a devida clareza. Esses editoriais, ao se afastarem da tônica dos objetivos da Revista - que é a imbricação entre educação e filosofia, e não simplesmente capitalismo e universidade - mostraram que, pelo menos por um período da publicação da Revista, os textos editoriais ficaram mais enfurecidos do que, necessariamente, sábios.

Contudo, antes de subdividir os editoriais da Revista analisada, melhor será considerar que alguns se enveredaram pela complexidade das práticas docentes associadas às políticas públicas para a Universidade, situando política e filosoficamente essas práticas e essas políticas; enquanto outros, cansados ou consentâneos com o tipo de produção atual, abandonaram qualquer tipo de análise crítica; outros, ainda, enveredaram-se pela análise do processo sócio-econômico e seus efeitos sobre os destinos da Universidade brasileira. Não são excludentes entre si, mas complementares, embora demonstrem os diferentes momentos vividos pela produção da Revista.

A reflexão que acabamos de fazer aponta para a necessidade de se aprofundar as diferentes etapas vividas pelo conjunto dos 
editoriais das revistas brasileiras. Assim, seria importante uma pesquisa que comparasse editoriais de outras revistas que tenham como alvo o público acadêmico, ou que pretendem ser porta-vozes dos anseios, reflexões, além de meios de divulgação das atividades desenvolvidas nas instituições universitárias. Assim, um trabalho que se propusesse a analisar os editoriais das Revistas Educação e Sociedade, dos cadernos do CEDES e da Revista Educação e Filosofia, por exemplo, poderia revelar aproximações e discordâncias, a fim de verificar sob quais perspectivas filosóficas, políticas e educacionais os editoriais se submetem. Poderia, também, fazer uma pesquisa que verificasse a relação dos editoriais com os artigos que a Revista reúne. Ou poderia ainda examinar como as polêmicas sobre a produção e divulgação do conhecimento são tratadas pelos mesmos. Enfim, há ainda uma infinidade de relações que podem ser aferidas na análise de editoriais.

\section{Referências}

BASTOS, M. Helena Camara. As revistas pedagógicas e a atualização do professor: a revista do ensino do Rio Grande do Sul (1951-1992). In: CATANI, Denice Barbara; BASTOS, M. Helena Camara (Org.). Educação em Revista: a imprensa periódica e a história da educação. São Paulo: Escritura, 1997.

CHARTIER, Roger. A história cultural: entre práticas e representações. Lisboa: Difel, 1990.

CHAUI, Marielna. A universidades em ruínas. In: TRINDADE, Hélgio (Org.). A universidade em ruínas. Petrópolis, RJ: Vozes; Rio Grande do Sul: CIPEDES, 1999.

CUNHA, Luiz A. reforma universitária em crise: gestão, estrutura e território. In: TRINDADE, Hélgio (Org.). A universidade em ruínas. Petrópolis, RJ: Vozes; Rio Grande do Sul: CIPEDES, 1999. 
FOUCAULT, M. História da sexualidade. v. II. Rio de Janeiro: Graal, 1985.

FOUCAULT, M. Microfísica do poder. Rio de Janeiro: Graal, 1979.

JAPIASSU, H. Dicionário básico de Filosofia. Rio de Janeiro: Jorge Zahar, 1996.

NÓVOA, Antonio. A imprensa de educação e ensino: concepção e organização do repertório português. In: CATANI, Denice Barbara; BASTOS, M. Helena Camara (Org.). Educação em Revista: a imprensa periódica e a história da educação. São Paulo: Escritura, 1997.

TRINDADE, Hélgio. As universidades frente à estratégia do governo. In: TRINDADE, Hélgio (Org.). A universidade em ruínas. Petrópolis, RJ: Vozes; Rio Grande do Sul: CIPEDES, 1999.

RISTOFF, Dilvo I. Privatização não faz escola. In: TRINDADE, Hélgio (Org.). A universidade em ruínas. Petrópolis, RJ: Vozes; Rio Grande do Sul: CIPEDES, 1999. 
ANEXO A - Tabela das seções presentes na Revista

\begin{tabular}{|l|l|c|}
\hline SEÇÕES & $\mathrm{N}^{\circ}$ DA REVISTA & TOTAL \\
\hline ARTIGOS & $1-33$ & 33 \\
\hline DEBATES & $1-8 ; 13,15-17,19,26$ & 13 \\
\hline COMUNICAÇÕES & $3-6,16,18-20,29,32,33$ & 11 \\
\hline RESENHAS & $1-16,18-33$ & 32 \\
\hline NOTÍCIAS & $1-3,26$ & 04 \\
\hline ENSAIOS & 16,17 & 02 \\
\hline ENTREVISTA & 20 & 01 \\
\hline TRADUÇÃO & $27 / 28$ & 01 \\
\hline
\end{tabular}


ANEXO B - Tabela com as resenhas publicadas por categorias de análise

\begin{tabular}{|c|c|c|c|c|c|}
\hline $\begin{array}{c}\mathrm{N}^{\circ} \mathrm{DA} \\
\text { REVISTA }\end{array}$ & \begin{tabular}{|l|} 
TOTAL DE \\
RESENHAS
\end{tabular} & EDUCAÇÃO & FILOSOFIA & $\begin{array}{c}\text { FILOSOFIA DA } \\
\text { EDUCAÇÃO }\end{array}$ & OUTROS \\
\hline 01 & 02 & -- & 01 & -- & 01 \\
\hline 02 & 03 & 02 & 01 & - & - \\
\hline 03 & 03 & 01 & -- & -- & 02 \\
\hline 04 & 04 & 03 & 01 & -- & - \\
\hline $05 / 06$ & 02 & -- & 01 & 01 & -- \\
\hline 07 & 03 & -- & 01 & -- & 02 \\
\hline 08 & 02 & 02 & -- & -- & - \\
\hline 09 & 02 & 01 & 01 & -- & -- \\
\hline $10 / 11$ & 01 & -- & 01 & -- & -- \\
\hline 12 & 02 & -- & 02 & -- & -- \\
\hline 13 & 03 & -- & 02 & -- & 01 \\
\hline 14 & 02 & 01 & 01 & -- & -- \\
\hline 15 & 03 & 03 & -- & -- & -- \\
\hline 16 & 03 & 01 & 01 & -- & 01 \\
\hline 18 & 01 & -- & -- & -- & 01 \\
\hline 19 & 03 & 01 & 01 & -- & 01 \\
\hline 20 & 05 & 01 & 03 & 01 & -- \\
\hline $21 / 22$ & 06 & -- & 03 & 01 & 02 \\
\hline 23 & 04 & 01 & 01 & 01 & 01 \\
\hline 24 & 13 & 07 & 05 & 01 & -- \\
\hline 25 & 07 & 03 & 02 & 01 & 01 \\
\hline 26 & 02 & -- & 01 & -- & 01 \\
\hline $27 / 28$ & 04 & 01 & 03 & -- & 01 \\
\hline \multicolumn{6}{|l|}{29} \\
\hline 30 & 04 & -- & 04 & -- & -- \\
\hline 31 & 03 & -- & 03 & -- & -- \\
\hline 32 & 02 & -- & 02 & -- & -- \\
\hline 33 & 02 & -- & 02 & -- & - - \\
\hline Total Geral & 92 & 28 & 43 & 06 & 15 \\
\hline
\end{tabular}


ANEXO C - Tabela dos artigos publicados

\begin{tabular}{|c|c|c|c|c|c|}
\hline $\begin{array}{c}\mathrm{N}^{\circ} \text { DA } \\
\text { REVISTA }\end{array}$ & \begin{tabular}{r|} 
TOTAL DE \\
RESENHAS
\end{tabular} & EDUCAÇÃO & FILOSOFIA & $\begin{array}{c}\text { FILOSOFIADA } \\
\text { EDUCAÇÃO }\end{array}$ & OUTROS \\
\hline 01 & 07 & 03 & 02 & 01 & 01 \\
\hline 02 & 09 & 05 & 03 & 01 & -- \\
\hline 03 & 07 & -- & 04 & 01 & 02 \\
\hline 04 & 12 & 06 & 03 & -- & 03 \\
\hline $05 / 06$ & 20 & 07 & 09 & 01 & 03 \\
\hline 07 & 15 & 05 & 08 & -- & 02 \\
\hline 08 & 12 & 04 & 04 & 02 & 02 \\
\hline 09 & 13 & 05 & 04 & 01 & 03 \\
\hline $10 / 11$ & 16 & 04 & 09 & -- & 03 \\
\hline 12 & 12 & 05 & 04 & 02 & 01 \\
\hline 13 & 16 & 06 & 07 & 02 & 01 \\
\hline 14 & 15 & 04 & 09 & 01 & 01 \\
\hline 15 & 10 & 05 & 03 & 02 & -- \\
\hline 16 & 13 & 04 & 06 & 02 & 02 \\
\hline 17 & 14 & 06 & 06 & 02 & -- \\
\hline 18 & 08 & 02 & 03 & 03 & -- \\
\hline 19 & 12 & 08 & 01 & 01 & 02 \\
\hline 20 & 13 & 06 & 03 & 03 & 01 \\
\hline $21 / 22$ & 15 & 08 & 03 & 03 & 01 \\
\hline 23 & 11 & 05 & 05 & -- & 01 \\
\hline 24 & 13 & 07 & 05 & 01 & -- \\
\hline 25 & 14 & 06 & 06 & 02 & -- \\
\hline 26 & 14 & 06 & 08 & -- & -- \\
\hline $27 / 28$ & 12 & 07 & 05 & -- & -- \\
\hline 29 & 14 & 08 & 06 & -- & -- \\
\hline 30 & 10 & 03 & 04 & 03 & -- \\
\hline 31 & 09 & 05 & 04 & -- & -- \\
\hline 32 & 07 & 03 & 04 & -- & -- \\
\hline 33 & 07 & 03 & 03 & 01 & -- \\
\hline Total & 350 & 146 & 140 & 35 & 29 \\
\hline
\end{tabular}

Educ. e Filos., Uberlândia, v. 20, n. 40, p. 111-136, jul./dez. 2006. 
Anexo D - Tabela dos textos publicados na seção de debates da revista por categoria de análise

\begin{tabular}{|c|c|c|c|c|c|}
\hline $\begin{array}{c}\mathrm{N}^{\circ} \text { DA } \\
\text { REVISTA }\end{array}$ & $\begin{array}{c}\text { TOTAL DE } \\
\text { RESENHAS }\end{array}$ & EDUCAÇÃO & FILOSOFIA & $\begin{array}{c}\text { FILOSOFIA DA } \\
\text { EDUCAÇÃO }\end{array}$ & OUTROS \\
\hline 01 & 04 & 03 & - & - & 01 \\
\hline 02 & 08 & 03 & - & 03 & 02 \\
\hline 03 & 06 & 03 & 01 & - & 02 \\
\hline 04 & 03 & 01 & 01 & 01 & - \\
\hline $05 / 06$ & 05 & 01 & 02 & 01 & 01 \\
\hline 08 & 03 & 02 & - & - & 01 \\
\hline 13 & 01 & - & - & 01 & - \\
\hline 15 & 01 & 01 & - & - & - \\
\hline 16 & 01 & 01 & - & - & - \\
\hline 17 & 01 & 01 & - & - & - \\
\hline 19 & 01 & - & - & 01 & - \\
\hline 26 & 01 & - & 01 & - & - \\
\hline 35 & 16 & 05 & 07 & 07 & \\
\hline
\end{tabular}

Anexo E - Quadro dos Editoriais

\begin{tabular}{|l|l|c|}
\hline RESPONSÁVEL & NÚMEROS & TOTAL \\
\hline A Diretoria & $02,29,31,32,33$ & 05 \\
\hline Geraldo Inácio Filho & $03,04,05 / 06,07,12,13,14,15,16,17,20,23$ & 12 \\
\hline Décio Gatti & $27 / 28$ & 01 \\
\hline Bento Itamar Borges & $21 / 22,24,26$, & 03 \\
\hline Humberto A. de Oliveira & $27 / 28$ & 01 \\
\hline Wagner de Mello Elias & 30 & 01 \\
\hline Marilza Abraão P. Rezende & $08,09,10 / 11$ & 03 \\
\hline Regina Célia de S. Feltran & 18,19 & 02 \\
\hline Não tem assinatura & 01 & 01 \\
\hline
\end{tabular}


Anexo F - Classificação dos editoriais por categorias de análise

\begin{tabular}{|l|l|l|c|}
\hline \multicolumn{2}{|c|}{ CATEGORIAS } & \multicolumn{1}{|c|}{ EDITORIAIS } & TOTAL \\
\hline Análise de & social e política & $5 / 6,03,04,07,08,09$, & 15 \\
\cline { 2 - 4 } conjuntura & $\begin{array}{l}\text { reflexão sobre a } \\
\text { educação e } \\
\text { universidade }\end{array}$ & $\begin{array}{l}10 / 11,13,14,15,16,18, \\
23,24,26,\end{array}$ & \\
\hline Informações sobre a revista & $\begin{array}{l}01,02,03,05 / 06,09,12, \\
15,17,18,19,20,21 / 22,\end{array}$ & 16 \\
& $24,25,27 / 28,31$ & \\
\hline $\begin{array}{l}\text { Apresentação dos textos } \\
\text { publicados }\end{array}$ & $\begin{array}{l}04,25,26,27 / 28,29,30, \\
31,32,33\end{array}$ & 09 \\
\hline
\end{tabular}

